\title{
O ENVOLVIMENTO DO PAPILOMAVÍRUS HUMANO NO CÂNCER DO COLO DO ÚTERO: ARTIGO DE REVISÁO
}

\author{
THE HUMAN PAPILLOMAVIRUS INVOLVEMENT IN THE CERVICAL \\ CANCER: REVIEW ARTICLE
}

\author{
Juliane Oliveira Brum ${ }^{1}$, Vera Regina Medeiros Andrade ${ }^{1}$
}

${ }^{1}$ Universidade Regional Integrada do Alto Uruguai e das Missóes, URI; Santo Ângelo, RS, Brasil.

\section{RESUMO}

Com o objetivo de revisar na literatura a história da descoberta do envolvimento do Papilomavírus Humano (HPV) no câncer do colo do útero foi realizada uma revisão narrativa da literatura nas bases de dados eletrônicas PubMed, Scielo, LILACS, utilizando palavras chave como células HeLa, Papilomavírus humano, HPV, coilocitose, câncer do colo do útero, DNA do HPV, partículas semelhantes a vírus VLP, vacina contra HPV. Na década de 70 Harald Zur Hausen desenvolveu estudos com amostras de células HeLa com o intuito de relacionar o HPV com o câncer de colo de útero. O HPV é uma das doenças sexualmente transmissíveis (DST) mais recorrente no mundo e está implicado no desenvolvimento do câncer do colo do útero. Para evitar a transmissão desse vírus é necessário a realização das prevençôes primárias e secundárias por meio da vacinação e utilização de preservativos durante as relaçôes sexuais, respectivamente. A realização da prevenção primária é importante, pois em função dela é possível impedir a infecção pelo HPV e a evolução para o câncer de colo de útero.

Descritores: Papillomaviridae, Neoplasia Intraepitelial Cervical, células HeLa, Vacinação.

\begin{abstract}
In order to review in the literature the history of the discovery of the involvement of Human Papillomavirus (HPV) in cervical cancer, a narrative review of the literature was carried out in the electronic databases PubMed, Scielo, LILACS, using keywords such as HeLa cells, Human papillomavirus, HPV, koilocytosis, cervical cancer, HPV DNA, VLP virus-like particles, HPV vaccine. In the 70's Harald Zur Hausen developed studies with samples of HeLa cells in order to relate $H P V$ to cervical cancer. HPV is one of the most recurrent sexually transmitted diseases (STDs) in the world and is involved in the development of cervical cancer. To prevent the transmission of this virus, primary and secondary preventions must be carried out through vaccination and the use of condoms during sexual intercourse, respectively. Performing primary prevention is important, as it is possible to prevent HPV infection and progress to cervical cancer.
\end{abstract}

Descriptors: Papillomaviridae, Cervical Intraepithelial Neoplasia, HeLa Cells, Vaccination. 


\section{INTRODUÇÃO}

Conforme dados epidemiológicos divulgados pelo Instituto Nacional do Câncer (INCA), o câncer do colo do útero é terceiro tipo de câncer mais frequente na população fermina, ficando apenas atrás do câncer de mama e colorretal. Além disso, são estimados cerca de 16.710 novos casos de câncer de cérvice para cada ano do triênio 2020-2022 ${ }^{1}$.

O Papilomavirus humano (HPV) é um vírus que possui uma fita dupla de DNA circular não envelopado, possui uma cápsula proteica com simetria icosáedrica. Além disso, seu genoma possui regiōes codificadoras divididas em precoce, codificam proteínas envolvidas na replicação e oncogênese viral e tardia que codificam proteínas que formam o capsídeo do vírus. Possui uma vasta família com cerca de 150 tipos de vírus que infectam o homem, sendo eles divididos em baixo e alto risco. Os vírus de baixo risco, sendo os mais frequentes os tipos 6 e 11, em geral causam verrugas e condilomas genitais. Os HPVs de alto risco estão envolvidos no câncer de colo de útero, câncer de pênis, anal e de orofaringite ${ }^{2}$, sendo muito importante conhecer o envolvimento do HPV no câncer do colo do útero. Dessa forma, o presente estudo teve como objetivo revisar na literatura a história da descoberta do envolvimento do HPV no câncer do colo do útero.

\section{METODOLOGIA}

Esta revisão foi realizada durante o desenvolvimento do projeto de extensão intitulado "Proposta de intervenção sobre o câncer do colo do útero por meio de informaçóes sobre a vacina contra o Papilomavírus Humano (HPV) para adolescentes”, no período de agosto de 2019 a julho de 2020, na Universidade Regional Integrada do Alto Uruguai e das Missões, Campus de Santo Ângelo, Rio Grande Sul, Brasil.

Foi realizada revisão narrativa da literatura em artigos científicos encontrados nas bases de dados eletrônicas PubMed, Scientific Electronic Library Online (Scielo), Literatura Latino-americana e do Caribe em Ciências da Saúde (LILACS), utilizando palavras chave como células HeLa, Papilomavírus humano, HPV, coilocitose, câncer do colo do útero, DNA do HPV, partículas semelhantes a vírus VLP, vacina contra HPV. Não houve delimitação de período na busca dos artigos, uma vez que foi acessado artigos históricos de Meissels (1976) ${ }^{3}$, Purola (1977) ${ }^{4}$ e Zur Hausen, (1977) ${ }^{5}$ que relacionaram o HPV com o câncer do colo uterino. Foram incluídos na pesquisa artigos originais e artigos de revisão, disponíveis com texto completo, publicados em periódicos nacionais e internacionais. A revisão começou abordando a epidemiologia do câncer do colo do útero no mundo e no Brasil; os aspectos históricos da descoberta do envolvimento do HPV no câncer cervical e da vida de Henrietta Larkes, cujas células foram utilizadas nestas pesquisas; a estrutura molecular do vírus Papilomavírus humano e câncer do colo do útero e prevenção como o exame de Papanicolaou e a vacina. 


\section{REVISÃO}

\section{Epidemiologia do câncer do colo do útero}

Conforme dados publicados pelo Instituto Nacional do Câncer (INCA), para o Brasil estima-se que para o próximo triênio (2020-2022) o número de novos casos de câncer cervical será de 16.590 com risco estimado de 15,43 casos a cada 100 mil mulheres. Além disso, o câncer do colo do útero é o segundo mais frequente nas regiōes norte, nordeste e centro-oeste. $\mathrm{Na}$ regiáo sul encontra-se em quarta posiçáo com risco estimado de 17,48 casos para cada 100 mil mulheres, seguido da regiáo sudeste que apresenta menor índice de câncer do colo do útero (Figura 1) ${ }^{1}$.

Figura 1 - Representação espacial das taxas ajustadas de incidência por 100 mil mulheres, estimadas para o ano de 2020, segundo Unidade de Federação, para câncer do colo do útero.

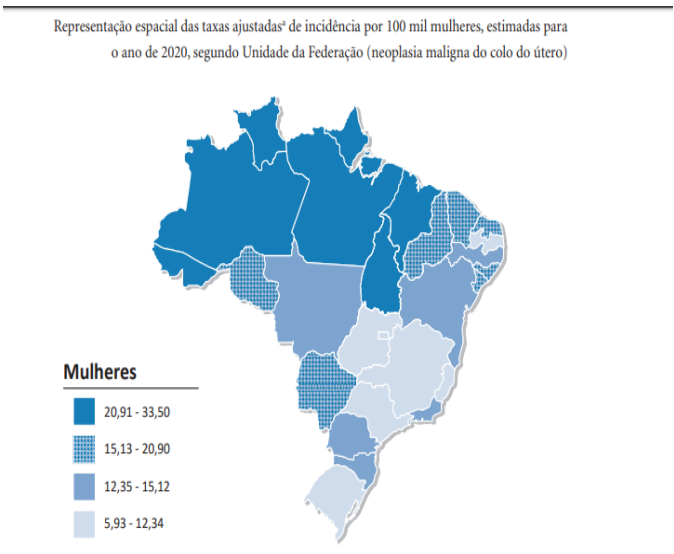

Fonte: BRASIL, 2019

\section{História}

Atualmente, está bem estabelecida a relação entre a infecção por certos tipos de HPV e o câncer do colo do útero. Porém, os estudos para se chegar a esta conclusão começam na década de 70, quando já era conhecido o envolvimento do HPV em verrugas comuns e genitais (condiloma acuminado). A partir daí vários pesquisadores como Zur Hausen, em 1974, com pesquisas realizadas para encontrar o DNA do HPV, em biópsias de câncer do colo do útero e por Meiseils e Fortin (1976) e Purola e Savia (1977), quando sugeriram que certas atipias em células do epitélio do colo do útero, até o momento, consideradas como lesôes pré-malignas, apresentavam aspectos citológicos equivalentes as células das lesôes verrucosas. Esse aspecto citológico atípico comum entre as lesôes foi à presença de células conhecidas como "coilócitos". Tais descobertas foram confirmadas por outros observadores, usando microscopia eletrônica ${ }^{3,6,4,7,5}$. 
Em 1974, Harald Zur Hausen realizou estudos a partir de amostras de células HeLa sobre a relação do HPV com o câncer de colo de útero. Começou a analisar essas células que o levou a constatar que o HPV estava envolvido na gênese do tumor ${ }^{5}$.

As células HeLa, começaram a ser cultivadas no ano de 1950, nos Estados Unido da América, quando Henrietta Larkes foi diagnosticada com câncer do colo do útero, por meio de biópsia. O material extraído de Henrietta foi utilizado em pesquisa e suas células foram cultivadas pelo cientista George Gey, que obteve sucesso com cultura de células cancerosas pela primeira vez e batizou esta linhagem de células com as primeiras sílabas do nome da paciente como HeLa ${ }^{8}$.

Em dezembro de 1976 os cientistas Meiseils e Fortin, e em janeiro de 1977, Purola e Savia, publicaram, quase que simultaneamente, que certas atipias visualizadas em células do epitélio do colo do útero, até o momento considerado como lesóes prémalignas, apresentavam aspectos citológicos equivalentes as células das lesōes verrucosas. Essa alteração citológica foi denominada de coilócito, o qual é um sinal citológico da presença do vírus na célula. $O$ vírus entra na célula da camada basal do epitélio, e dentro do núcleo dessa célula, produz novas cópias virais, permitindo que a célula se diferencie para as camadas superficiais apresentando "coilocitose", e outras alteraçóes como binucleaçáo e multinucleação (Figura 2) 6,4,7.

Figura 2 - Fotos de microscopia óptica (400X) de células escamosas esfoliadas da mucosa da cérvice uterina apresentando alteraçōes celulares coilocíticas compatíveis com infecção pelo Papilomavirus bumano (HPV)

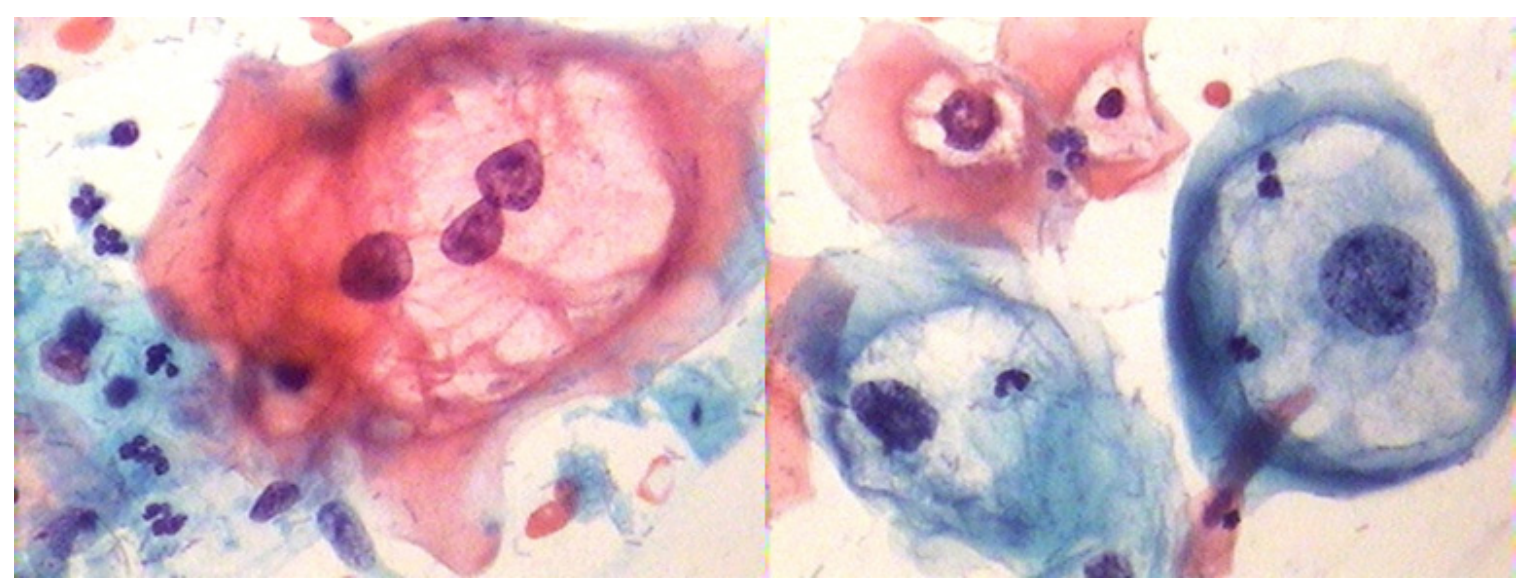

Fonte: Arquivo pessoal Professora Vera Andrade.

Após vários estudos moleculares sobre o vírus, os cientistas constataram que o vírus HPV é necessário, porém não suficiente para desenvolver câncer cervical, sendo necessários outros fatores para a manifestaçáo do mesmo. Cerca de $40 \%$ das mulheres sexualmente ativas são infectadas pelo $\mathrm{HPV}^{6}$. 


\section{Papilomavirus humano}

O HPV pertence à família Papillomaviridae, e com base nas pesquisas, já foram identificados mais de 200 tipos de HPV que infectam o homem, mamíferos não humanos, aves e répteis, sendo que em humanos, mais de 100 tipos foram identificados e divididos em dois grupos conforme seu potencial de oncogenicidade, como HPVs de alto e baixo risco. Os de alto risco são aproximadamente 40 tipos, que infectam a região anogenital, sendo cerca de 18 oncogênicos: HPV16, 18, 26, 31, 33, 35, 39, 45, 51, 52, 53, 56, 58, 59, 63, 66, 68 e 82. Os tipos de HPV de baixo risco são 6, 11, 42, 43, 44, 54, 70, 73, entre outros ${ }^{9,2}$.

O HPV possui um genoma constituído por um DNA dupla fita e circular. Possui regióes codificadoras, divididas em precoce (early) e tardia (late). $\mathrm{Na}$ região precoce estão os genes E1, E2, E4, E5, E6 e E7. Os genes E1 e E2 reúnem proteínas que realizam a replicação do HPV, e o E2 também é responsável pela transcrição do DNA. A proteína produzida no gene E4 tem função de maturar e a de liberar as partículas do vírus. Os genes E5, E6 e E7 sintetizam proteínas envolvidas na transformação celular. Os genes L1 e L2 da regiáo tardia realizam a formação do capsídeo o qual envolve o DNA do vírus HPV. O capsídeo possui 360 cópias da proteína principal capsídica, L1, a mesma fica organizada em 72 pentâmeros numa rede icosaédrica e 12 cópias da proteína capsidial menor L2 (Figura 3) ${ }^{2,10}$.

Figura 3 - Esquema do genoma do Papilomavirus humano 16.

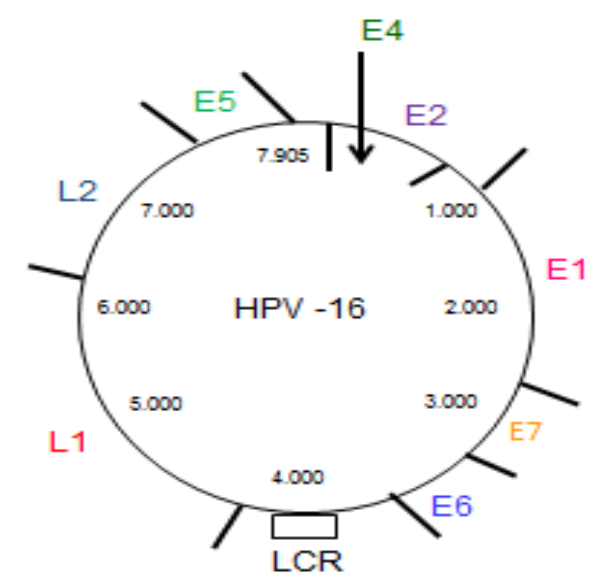

Abreviaçôes: LCR: Long Control Region. Fonte: Os Autores.

Com a descoberta de que a proteína L1 se organizava em partículas de estrutura icosaédrica, semelhantes ao capsídeo viral, ou virus-like particles (VLPs), porém sem o DNA do vírus, possibilitou o avanço do conhecimento sobre a imunogênese do HPV e o posteriormente a fabricação de vacinas profiláticas ${ }^{7}$. 


\section{Papilomavírus humano e câncer do colo do útero}

O HPV afeta as células basais do tecido epitelial escamoso estratificado (Figura 4). Quando ocorre a diferenciação celular através de sucessiva mitose, o vírus modifica o DNA presente no interior das células, trocando os genes do hospedeiro pelo seu. Dessa forma, quando a célula se dividir ela terá consigo o DNA do HPV ${ }^{6,4,7}$.

Figura 4 - Esquema do tecido epitelial escamoso estratificado mostrando o acesso do Papilomavírus humano à célula basal.

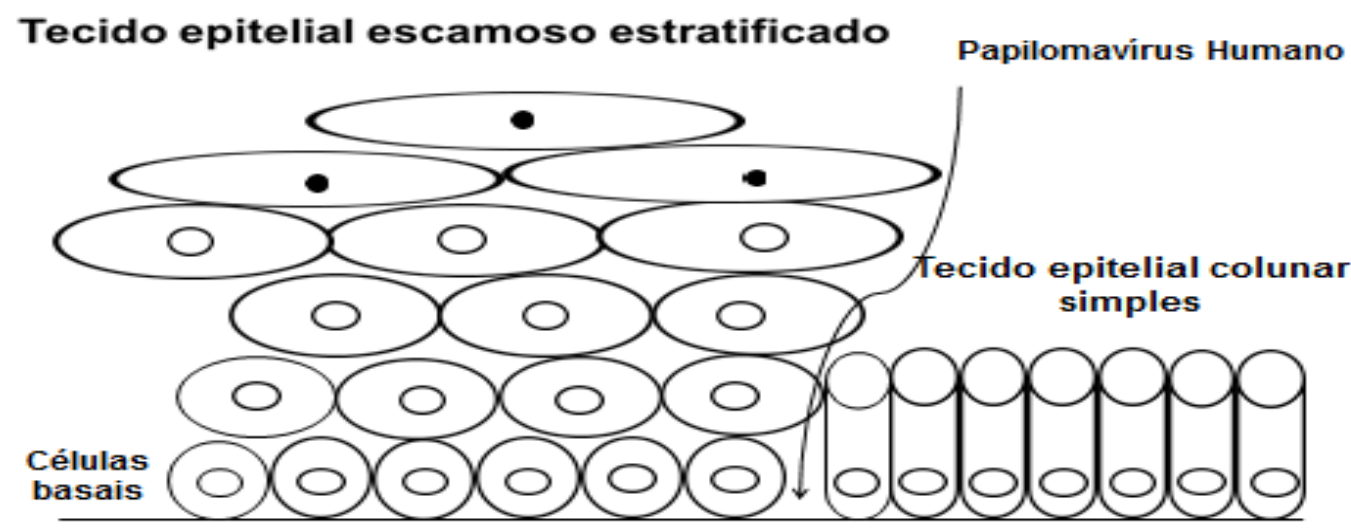

Fonte: Os autores.

Náo é necessário que o HPV evolua para uma alteração maligna, quando as lesóes são identificadas como de baixo grau em geral regridem sozinhas, porém em alguns casos persistem e transformam-se em câncer. Os fatores que influem na aquisição do vírus giram em torno do número de parceiros sexuais, a idade em que ocorreu a primeira relação sexual e o comportamento dos parceiros masculinos. $\mathrm{O}$ vírus $\mathrm{HPV}$ pode ser transmitido por contato direto com órgáos genitais durante o coito sexual, a prática de sexo anal pode resultar em infecçáo e neoplasias anais e possivelmente pelo sexo oral. É importante lembra que o HPV não necessariamente irá se manifestar logo após a contaminação, o vírus pode ficar em estado se latência em média de 6-12 meses, se for do tipo ontogênico pode permanecer por um período maior. Para que aconteça a evolução de uma infecção por HPV para uma neoplasia cervical, são necessários cofatores como uso de contraceptivos orais por período muito prolongado, tabagismo, imunossupressão, infecçôes por outras doenças sexualmente transmissíveis e deficiências nutricionais. Entretanto, fatores como idade da sexarca, o número de parceiros sexuais e história com DSTs devem-se ao processo de aquisição do HPV, porém não são consideradas cofatores para a progressão da infecção ocasionada pelo vírus ${ }^{11}$.

\section{Prevençáo}

As formas de prevenção contra o HPV são divididas em primária, que consiste na imunização por meio de vacinas e a secundária realizada por exames preventivos. 
Esses exames compreendem o exame preventivo de câncer de colo de útero ou exame Papanicolaou, os exames de colposcopia e peniscopia. O exame Papanicolaou é utilizado como rastreamento populacional, sendo que por meio dele é possível observar algumas alteraçôes celulares no trato genital, diagnosticar e acompanhar o desenvolvimento da infecçáo. O exame preventivo é indicado para mulheres com idades entre 25 e 59 anos, ou que já iniciaram sua vida sexual. Deve ser feito anualmente, e após dois exames consecutivos com resultados normais, ele pode ser feito a cada três anos ${ }^{12,10,13}$.

Dentre as vacinas contra HPV estão disponíveis: a vacina bivalente contra HPV, produzida por GlaxoSmithKline, a vacina quadrivalente e a nonavalente produzidas pela Merck Sharp and Dohme. As vacinas foram feitas a partir da proteína L1 do capsídeo viral, por tecnologia de DNA recombinante, obtendo partículas semelhantes aos vírus ou VLP. As VLPs são partículas que não possuem DNA e não provocam infecção, entretanto induzem a produção de anticorpos contra os tipos específicos de HPV contidos na vacina. Dessa forma, a resposta imunológica específica de memória é gerada baseada em anticorpos neutralizantes contra as proteínas L1 do capsídeo viral. Todavia, a imunização contra a infecção vai depender da quantidade de anticorpos sintetizados, a presença dos anticorpos no local da infecçáo e a sua persistência durante um longo período de tempo 12,10 .

A vacina Cervarix ${ }^{\circ}$ (bivalente) possui antígenos na forma VLP tipos de HPV 16 e 18, os quais são os responsáveis pelas lesôes genitais pré-cancerosas de alto grau do colo do útero e câncer do colo do útero, além disso, é um adjuvante para proporcionar o aumento a sua imunogenicidade ${ }^{12,10}$.

A vacina quadrivalente Gardasil ${ }^{\circ}$ contém antígenos dos tipos de HPV 6, 11, 16 e 18 e um adjuvante para aumentar a sua imunogenicidade. Sua administração pode ser em duas ou três doses, podendo variar de acordo com a idade do paciente. Dessa forma, se forem duas doses, o intervalo deve ser de seis meses e quando forem três doses a primeira é na data em que o paciente escolher, a segunda é aplicada dois meses após a primeira, e a terceira, seis meses depois da primeira dose. A aplicaçáo é recomendada para pacientes do sexo feminino dos 9 aos 26 anos e masculino de 11 a 26 anos. A mesma está disponível no sistema público de saúde, no Brasil (SUS), sendo recomendada pelo calendário vacinal oficial do país ${ }^{12,10}$.

A vacina contra o HPV nonavalente (Gardasi ${ }^{\circ}$ ) dispóe de antígenos dos tipos de HPV 6, 11, 16, 18, 31, 33, 45, 52 e 58. Essa vacina pelo fato de ser nova no mercado ampliou a proteçáo contra o HPV, pois inclui cinco novos subtipos na proteção com o HPV, reduzindo, segundo dados de seu fabricante, em aproximadamente $90 \%$ o risco de desenvolvimento de câncer do colo útero. Já aprovada no Brasil, porém ainda não está disponível ${ }^{12,10}$. 


\section{CONSIDERAÇÓESS FINAIS}

A prevenção primária é de suma importância, pois por meio dela é possível impedir a infecção pelo HPV e a evolução para o câncer de colo de útero. As formas de prevenção primária são pelo uso de camisinha, que é indispensável durante as relaçóes sexuais, pois com ela pode-se reprimir a transmissão, principalmente na primeira relação da menina quando normalmente ocorre a contaminação pelo HPV; e a vacina contra o HPV, disponível no Sistema Único de Saúde para meninas de 9 a 15 anos e meninos de 11 a 15 anos. A prevenção secundária é realizada pelo exame preventivo do câncer do colo do útero ou exame de Papanicolaou, e exame de peniscopia. Desta forma, é necessária a realização periódica do exame Papanicolaou para evitar um diagnóstico tardio.

\section{REFERÊNCIAS}

1. Brasil Ministério da Saúde. Instituto Nacional de Câncer José Alencar Gomes da Silva. Estimativa 2020: incidência de câncer no Brasil / Instituto Nacional de Câncer José Alencar Gomes da Silva. - Rio de Janeiro: INCA, 2019.

2. Vasquez-Bonilla, WO, Rotela-Fisch V, Ortiz-Martínez Y. Virus del papiloma humano: revisión de la literatura. CIMEL 2017; 22 (1): 72-76.

3. Meisels A, Fortin R. Condylomatous lesions of the cervix and vagina. I. Cytologic patterns. ACTA Cytol, 1976;20:505-509.

4. Purola E, Savia. E. Cytology of gynecologic condyloma acuminatum. ACTA Cytol $1977 ; 21: 26-31$.

5. zur Hausen H. Human Papilloma viruses and Their Possible Role in Squamous Cell Carcinomas. Curr Top Microbiol Immunol. 1977; 78: 1-30.

6. Munhoz D, Cardeal LBS, Maria-Engler SS. Carcinoma Escamoso e Atipias. In: Consolaro MEL, Engler SSM [organizadores]. Citologia Clínica cérvico-vaginal: texto e atlas. São Paulo: Roca, 2014.

7. Silva Neto JC. Citologia Clínica do trato genital feminino. Rio de Janeiro: Revinter; 2012.

8. Caldas C. Resenha: Vida, morte e imortalidade: desvendando a história das células HeLa - Revista Cienc. Cult. vol.62 no.2 São Paulo, 2010

9. Goetz E, Andrade VRM. Conhecimento e adesão de crianças e adolescentes à vacina contra o Papilomavírus humano. Vivências. Vol. 14, N.26: p.110-121, Maio/2018 
10. Santos ALB, Monteiro CM.; Vargas FA. Papilomavírus humano: uma revisão narrativa da literatura - RICSB, 2018.

11. Carrillo FJO, Regil DBG, Jiménez MTV. Infección por virus del papiloma humano en mujeres y su prevención. Gaceta Mexicana de Oncología. 2015;14(3):157-163.

12. Fiorin T, Kuhn FR, Silva KF, Wagner T, Franco BV, Mascarello MZ, Kowalski L, Andrade VRM. Compartilhando saberes de educação em saúde para adolescentes sobre a vacina contra o Papilomavírus humano. Vivências. 2019; 15 (28):68-75.

13. Schneider DR, Monteiro CM, Andrade VRM. Avaliação do conhecimento de adolescentes sobre a infecçáo pelo papilomavírus humano antes e depois de uma intervenção educativa. RICSB. 2017; 1 (1):25-31. DOI - 10.31512/ricsb.v1i01.2459

Autor Correspondente: Vera Regina Medeiros Andrade

E-mail:vandrade@san.uri.br

Recebido em: 2020-07-09

Aprovado em: 2020-08-29 